\title{
Monográfico
}

\section{0 años después. Expectativas y (duras) realidades en comunicación política}

\author{
20 years later. Expectations and (harsh) realities in political \\ communication
}

\author{
Dr. Rubén Arnoldo González \\ Benemérita Universidad Autónoma de Puebla (BUAP) México. \\ ruben.arnoldo.gonzalez@gmail.com \\ https://orcid.org/0000-0002-6758-5328 \\ Dr. Martín Echeverría \\ Benemérita Universidad Autónoma de Puebla (BUAP). México. \\ echevemartin@yahoo.com.mx \\ https://orcid.org/0000-0001-6071-8725
}

\section{PRESENTACIÓN}

Veinte años es un periodo razonable para esperar avances políticos y sociales en cualquier país. Particularmente en México, durante dicho periodo transcurren poco menos de tres sexenios medida tradicional de los ciclos del poder- durante los cuales los compromisos y oportunidades de iniciar, continuar o consolidar mejoras parecieran suficientes. En lo que respecta a la dimensión democrática de la comunicación política y el periodismo, la perspectiva de un avance o mejora en los últimos veinte años, los de la transición democrática, es por lo menos ambivalente y en algunos casos, decepcionante.

El 3 de julio de 2020 marcó el 20 aniversario de la transición mexicana a la democracia, cuando fue elegido Vicente Fox del Partido Acción Nacional, primer partido opositor que resultó ganador tras 70 años de gobiernos ininterrumpidos del Partido Revolucionario Institucional. Durante ese tiempo dicho partido hegemónico erigió controles cuasi dictatoriales sobre varios sectores y libertades sociales, a cambio de una estabilidad política y económica que se deterioró profundamente hacia mediados de los años noventa. En consecuencia, hubo expectativas elevadas de cambio positivo a raíz de esa primera transición, que incluía, entre otras, el ejercicio efectivo de la libertad de expresión y prensa.

Apenas unos años antes de la transición, la prensa estaba fuertemente controlada en favor del régimen -con cobertura oficialista y falta pluralidad en sus páginas- y acaso existía un puñado de rotativos independientes. El desvanecimiento de dichas condiciones era esperable una vez que las viejas bases del régimen autoritario se desvanecían, y las nuevas tomaban forma. Sin embargo, este vuelco no se materializó del todo. 
Si bien una buena parte de los medios se abrieron a las distintas opciones políticas y sociales, se trataron de independizar del financiamiento gubernamental, y atendían mejor las necesidades de una naciente ciudadanía democrática, diversos problemas se han investigado respecto a un desempeño democrático accidentado, de los que señalamos tres.

En primer lugar, el desempeño oficialista e instrumentalizado del pasado a nivel federal no se retiró a nivel local; los gobiernos estatales siguen sujetando medios, comprando líneas editoriales, y restringiendo o difamando a las voces opositoras a su conveniencia. A su vez, los medios locales siguen ofertando su línea editorial al mejor postor, distorsionando selectivamente la agenda pública y precarizando la profesión periodística, al ser indiferentes a un mercado de lectores que demanden buen periodismo. La relación de complicidad entre ciertos gobiernos y ciertos medios, de espaldas al interés público, más bien se sofisticó con la adopción de mecanismos legales que simulan la regularización de sus relaciones institucionales -convenios, transparencia gubernamental-, pero que en realidad le proporcionan una pátina de legalidad a una relación tan perniciosa como en el pasado.

En segundo lugar, la liberalización económica que precedió a la transición, en ocasiones desbocada, dio pie a una excesiva comercialización de los medios, donde el motivo de beneficio ha rivalizado y ocasiones achicado al interés público. En esa concepción de la información primordialmente como mercancía, la tematización y cobertura mediática ha obedecido a criterios de rentabilidad basados en el sensacionalismo, simplificación, personalización y espectacularización de la realidad política. Durante los veinte años de la transición las fronteras entre política y espectáculo se diluyeron -personajes de la farándula incursionando exitosamente en puestos públicos, políticos proyectándose en espacios de entretenimiento o bajo narrativas de telenovela- y se afianzaron géneros de alto impacto mediático, tales como los video escándalos, que combinan el desenmascaramiento de la investigación periodística con el morbo de un reality show.

Finalmente, la retirada de una autoridad central de la vida periodística abrió la posibilidad de que el crimen organizado ocupe su lugar y ejerza su dominio. México es actualmente el país más riesgoso para ejercer la profesión, con decenas de casos documentados de homicidios, desapariciones y agresiones a periodistas. La crónica roja de los últimos veinte años a este respecto dibuja una trayectoria de incremento de agresiones, respuesta tardía e insuficiente de la autoridad para atenderlos, y el fracaso sostenido del Estado mexicano para atajarlas. En un país en donde los periodistas son en buena medida estigmatizados como un grupo servil al poder, la indignación social hacia este fenómeno es mucho menor respecto a las agresiones cometidas hacia otros grupos y hacia otras libertades, lo cual contribuye a prolongarlo.

Más allá del ámbito periodístico, la arena más visible y delicada de la esfera pública, otras dimensiones de la comunicación política también han experimentado transformaciones en términos de formatos y plataformas. En consonancia con un periodismo de talante comercial, se sigue que los mensajes electorales e incluso gubernamentales también se han compenetrado con contenidos otrora exclusivos del dominio del entretenimiento. Candidatos o gobernantes en programas de espectáculo o de la mano de celebridades públicas, en sus programas o perfiles de redes socio-digitales; políticas públicas promovidas en telenovelas; y ficción cinematográfica o televisiva acerca de acontecimientos y relaciones políticas. La manera en que las audiencias, particularmente las despolitizadas, se vinculan con la política se diversificó ampliamente bajo 
estos formatos, independientemente de los problemas que ello pudiera acarrear en términos de simplificación o esquematismo de lo político.

El modelo de comunicación política, entendido en México primordialmente como la regulación equitativa de la publicidad política en televisión, se transformó de una relación laisez faire de compra venta de tiempo aire -vinculado a menudo con la transferencia de recursos públicos de los partidos a las televisoras- a una asignación estatal del recurso audiovisual bajo reglas y supervisión estricta. Aunque el Estado mexicano integró por mandato constitucional a los debates presidenciales a la dieta informativa de campaña, lo cierto es que preservó el problema de la saturación de spots televisivos durante la campaña -también llamado espotización- que amenaza con volver irrelevantes a estos mensajes, en virtud de su excesiva cacofonía.

Mención aparte merece la incursión de Internet en el espacio público mexicano. Aunque hubo una experiencia pionera previa a la transición democrática -teniendo al Ejército Zapatista de Liberación Nacional en 1994 como su principal usuario- el auge de la web y posteriormente de las redes sociales ha sido exponencial, al grado de que una buena parte de la conversación nacional y la persuasión pública tiene su epicentro en el espacio digital. Con todo, el estallido de una tecno o ciber-política a la mexicana también ha tenido claroscuros. Por un lado, agentes interesados y partidos políticos reproducen las estrategias de negatividad desplegadas en los "viejos" medios, e incurren en nuevas formas de envilecimiento del espacio público, en forma de acarreo digital -o bots-, campañas negras, desinformación y acoso cibernético.

Pero en sentido contrario, existen ejemplos fascinantes de lo que la sociedad civil ha podido lograr cuando se apropia y empodera a partir de las redes sociales. Los movimientos \#YoSoy132, por la democratización de los medios de comunicación, el \#YoTambiénSoyTwitTerrorista, para la defensa de la libertad de expresión en Twitter frente a la censura y represión del gobierno veracruzano, las comunidades virtuales \#AyotzinapaSomosTodos y \#YaMeCansé como una expresión de indignación y exigencia de justicia ante la falta de resultados del gobierno frente a la desaparición de los normalistas de Ayotzinapa, así como el movimiento \#EINueveNadieseMueve, en protesta por la ola de feminicidios acaecidos en los últimos años, demuestran la posibilidad de una democracia viva y participativa a partir, en buena medida, de las redes socio-digitales.

Como es notorio, la transición democrática no detonó una sucesión de avances y resoluciones a los antiguos problemas de libertad de expresión y derecho a la información mexicanos. En algunas ocasiones subsanó deudas institucionales y legales, pero en otras introdujo problemas cuya existencia o gravedad no tiene precedentes. Por otro lado, los últimos veinte años vieron el surgimiento de transformaciones en los medios tradicionales y las audiencias, así como la irrupción y disrupción de las tecnologías digitales que en buena medida transformaron el panorama y lo complejizaron aún más. Es por ello que los últimos veinte años no sólo representan un periodo definido de avances, pendientes y retrocesos, que requieren un análisis pausado, sino un lapso de cambio intenso en las estructuras y prácticas comunicativas que a veces agudizan, y otras atenúan, varios de los desafíos que tiene la comunicación política mexicana para ser más democrática.

En función de esta complejidad, el presente dossier de Pangea presenta una serie de trabajos retrospectivos y panorámicos acerca de las expectativas y resultados de la transición democrática en términos de comunicación y periodismo políticos. En ese sentido, esta compilación incluye 
cinco trabajos que observan dicho fenómeno desde diferentes perspectivas. El texto de Manuel Alejando Guerrero sirve como introducción, puesto que el autor ofrece una mirada abarcadora del sistema mediático mexicano en su conjunto; el cual presenta avances y retrocesos importantes en materia de cobertura de temas políticos.

Por su parte, Grisel Salazar presenta los resultados de un vasto análisis de contenido de la cobertura de actores provenientes de la sociedad civil en los principales periódicos de cada estado de la República. Los resultados indican que la presencia de dichos actores sigue siendo más bien marginal y coyuntural, aunque se percibe una mayor pluralidad en cuanto a las voces que tuvieron cabida en las notas (empresarios, ONG's, magisterio...).

Salvador de León parte desde una mirada eminentemente local para evaluar las condiciones de la protección a la libertad de expresión en México. De tal suerte, en su trabajo revisa minuciosamente los avances en las legislaciones estatales encargadas de salvaguardar el ejercicio periodístico, y los compara con las condiciones reales en las que los medios informativos realizan su trabajo.

También desde un punto de vista local, Gabriel Corral estudia el caso de la prensa queretana y su audiencia. Los hallazgos de su investigación indican que los periódicos de dicha entidad continúan reproduciendo el discurso del gobierno estatal en turno, por lo que no han permitido el acceso a la esfera pública a sectores silenciados de la población. Como resultado, los ciudadanos no muestran mayor interés en temas de política, pues su mayor participación se limita a votar en las elecciones.

Finalmente, el presente número especial cierra con el trabajo de Frida Rodelo, quien toma como objeto de estudio a la sátira política para evaluar los márgenes de libertad en los que desarrolla la expresión de las opiniones políticas en la televisión mexicana. La autora concluye que los programas que recurren a dicho género presentan contenidos determinados por las relaciones clientelares entre las televisoras y los actores políticos, la autocensura, y las orientaciones políticas de los medios, entre otros factores. 